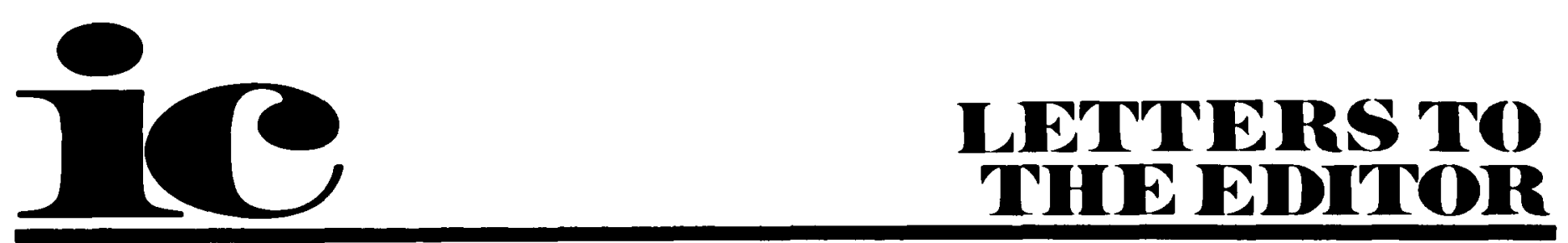

\section{Restriction of Hospital Employees with Active HSV}

\section{To the Editor:}

In 1977, the American Academy of Pediatrics recommended that neonates be separated from all sources of herpetic infections, including employees and mothers. ${ }^{1}$ Many centers have not followed these suggestions, presumably due to lack of data documenting transmission of Herpes simplex virus (HSV) in hospitals. ${ }^{2}$ The recent review in Infection Control of The Nursing Clinics of North America: Symposium on Infection Control likewise questioned the validity of our statements concerning restriction of hospital employees with active HSV from nurseries, delivery rooms, or oncology units. ${ }^{3}$ There is sufficient information now available concerning nosocomial transmission of $\mathrm{HSV}$ in nurseries to support our position.

Horizontal transmission of $\mathrm{HSV}$ in hospitalized newborns has been suggested by epidemiologic studies since the mid-1970s. ${ }^{4}$ Until recently, definitive proof was hampered by an inability to distinguish between epidemiologically related and unrelated HSV isolates. Electrophoresis of virusspecific DNA cleaved by restriction endonucleases will separate and identify epidemic from nonepidemic strains of HSV-1 and HSV-2. Using restriction endonuclease techniques, Linnemann and co-workers demonstrated horizontal transmission of HSV-1 from a father to a newborn in a neonatal nursery. A second neonate also harbored the epidemic strain, but the mode of transmission in that instance was not entirely clear. ${ }^{5}$ Adams et al recently reported a series of acute herpetic infections occurring among nurses and patients in a pediatric intensive care unit. Restriction endonuclease analysis showed two clusters of infections were caused by different epidemic strains of HSV-l. There was clear epidemiologic and biologic evidence of cross-infection between employees and patients. ${ }^{6}$ Similar evidence or hospital transmission of HSV in oncology units and delivery rooms has not yet been documented. Nevertheless, we consider these high risk areas for nosocomial transmission. We urge that infection control practitioners and committees carefully reexamine their current hospital guidelines for HSV.

\section{REFERENCES}

1. Standards and Recommendations for Hospital Care of Newborn Infants, ed 6. Evanston, Illinois, American Academy of Pediatrics, 1977.

2. Schreiner RL, Kleiman MB, Gresham EL: Maternal oral herpes: Isolation policy. Pediatrics 1979; 63:247-249.

3. Bolyard E: The nursing clinics of North America: Symposium on infection control, book review. Infect Control 1981; 2:446. 448.
4. Light IJ: Postnatal acquisition of herpes simplex virus by the newborn infant: A review of the literature. Pediatrics 1979; 63:480-482.

5. Linnemann CC, Buchman TG, Light IJ, et al: Transmission of herpes simplex virus type $l$ in a nursery for the newborn. Identification of viral isolates by D.N.A. "finger printing." Lancet 1978; 1:964-966.

6. Adams G, Stover BJ, Keenlyside RA, et al: Nosocomial herpetic infections in a pediatric intensive care unit. $A m J$ Epidemiol 1981; 113:126-132.

Lawrence R. Crane, M.D. Hospital Epidemiologist Assistant Professor of Medicine Wayne State University School of Medicine Detroit, Michigan

Barbara T. Hazuka, B.S.N. Infection Control Practitioner Children's Hospital of Michigan Detroit, Michigan

Candace Friedman, M.P.H. Epidemiologist University Hospital Ann Arbor, Michigan

\section{Cracked Infusion Bottles}

\section{To the Editor:}

As medical technology advances, physicians and nurses may be confronted with previously unrecognized infection control problems. Cracks in infusion bottles leading to microbial contamination of solutions contained within are a well-recognized potential source of hospital-associated bac- 
teremia.' We have recently traced similar episodes of bacteremia to cracked Swan-Ganz catheter hubs and wish to alert the medical community to this previously unreported nosocomial problem.

During October and November 1981, two patients with congestive heart failure and one with upper GI bleeding had Swan-Ganz catheters inserted for monitoring left atrial pressures and measuring cardiac outputs. Within two to four days after insertion of the catheters, each of the patients developed bacteremia. Bacteremias were caused by Serratia marcescens in two cases and by Staphylococcus aureus in one. Careful review of their case records and discussions with the nursing staff revealed that cracks in the Swan-Ganz catheter hubs of all three patients had been detected 24 to 48 hours prior to the bacteremic episodes. Furthermore, on numerous occasions the catheters had been improperly disconnected to inject infusate for cardiac output measurements. Eventually each of the catheters was removed and returned to the manufacturer for analysis.

These three cases illustrate the potential of Swan-Ganz catheters for serving as a source of nosocomial bacteremia and suggest the need for careful daily inspection of such devices. If structural defects are observed the defective systems should be removed as quickly as possible to prevent hospital-acquired bacteremia.

\section{REFERENCE}

1. Maki DG, Goldmann DA, Rhame FS: Infection control in intravenous therapy. Ann Intern Med 1973; 79:867-887.

Beverly Gray, R.N. Infection Control Nurse VA Medical Center Dallas, Texas

\section{Laundry Chute Cleaning Recommendations}

\section{To the Editor:}

Pursuant to the reply in the "Letters to the Editor" column in the March/ April 1982 issue of Infection Control regarding the cleaning of laundry and trash chutes, my staff and I would like to comment.

The Pennsylvania Department of
Environmental Resources in 1968 implemented a comprehensive program in environmental sanitation in hospitals. Our staff of Hospital Consultants, Sanitarians with advanced degrees in Public Health and Environmental Health, performed surveys and provided consultation on environmental problems within the hospitals. In 1978, because of budgetary problems, the hospital program was dropped. The Hospital Consultants were then assigned to the Nursing Home Program where similar services were provided.

We have always strongly recommended the need for a programmed cleaning and maintenance schedule for laundry chutes within medical care facilities. Even though all linens should be bagged before they are deposited in a chute, lint is generated and adheres to the side walls and door openings on the chute. If the laundry is wet or soiled, bacteria can readily be disseminated through the bag and attach itself to the lint. The resulting air movement via piston action as bagged linen is dropped down the chute could result in the spread of microorganisms throughout the facility. Because of these conditions, we recommend cleaning of chutes on a monthly basis, or more frequent, if necessary.

As for method of cleaning, we, too, have suggested the lowering of a small person on a rope to physically scrub the chute. A more effective procedure, however, is the use of a rotating spray head on a hose with high water pressure which can be lowered down the chute. A combination detergentdisinfectant administered by a hose proportionator built into the system is also recommended. Furthermore, a nozzle at the top of the chute which can be turned on after the detergentdisinfectant has been sprayed into the chute would be ideal. A floor drain in the collection room at the chute discharge area is necessary with this type of system.

Another means of controlling the potential spread of contaminated air and lint is the installation of a small exhaust fan at the top of the chute, which, in effect, creates a negative pressure in the chute.

The ultimate solution, as indicated in your article, is to exclude the use of chutes. Not only will it eliminate the need for cleaning, but it will remove a potential safety and fire hazard and a potential spreader of contaminated air.

Kenneth W. Hoeh, M.S.E.H.

Chief

Institutions and Shelter Section Commonwealth of Pennsylvania Department of Environmental Resources Harrisburg, Pennsylvania

\section{Gastrointestinal Colonization}

\section{To the Editor:}

Christensen et al state in their March/April 1982 article, "Epidemic Serratia marcescens in a Neonatal Intensive Care Unit: Importance of the Gastrointestinal Tract as a Reservior"1 that "although adult gastrointestinal colonization is occasionally reported, it is not considered epidemiologically significant." This is in conflict with our reported experience. ${ }^{2}$

In our study, conducted in a Veterans Administration Hospital, we prospectively sampled the stools from 57 patients hospitalized on wards involved in an outbreak of multiplyresistant Serratia marcescens. We were able to demonstrate that five of these patients had become colonized and that three of these later developed extra-intestinal colonization and/or infection which included urinary tract and wound infections.

Thus, it is clear that despite the investigations referenced by Christensen et al, adult gastrointestinal colonization is epidemiologically significant, i.e., the fecal reservoir in adults is as important for nosocomially acquired Serratia marcescens infections as it is for the other Enterobacteriaceae.

\section{REFERENCES}

1. Christensen GD, Korones SB, Reed L, et al: Epidemic Serratia marcescens in a neonatal intensive care unit: Importance of the gastrointestinal tract as a reservoir. Infect Control 1982; 3:127-133.

2. Jones SR, Amon M, Falvey C, et al: Serratia marcescens colonizing of the gut. Lancet 1978; 1:1105.

Stephen R. Jones, M.D. Chief-Department of Medicine Consultant-Infectious Diseases Good Samaritan Hospital \& Medical Center Portland, Oregon 